\title{
LEGAL ASPECTS ON ENVIRONMENTAL NOISE AND URBAN SOUNDSCAPE REHABILITATION IN MEDITERRANEAN COUNTRIES: THE CASE OF GREECE
}

\author{
KONSTANTINOS VOGIATZIS ${ }^{1} \&$ KYRIAKOS PSYCHAS ${ }^{2}$ \\ ${ }^{1}$ University of Thessaly, Department of Civil Engineer, Volos Greece. \\ ${ }^{2}$ Special advisor to the Minister of the Environment Energy \& Climate Change.
}

\begin{abstract}
Noise is an important environmental factor affecting the degradation of the urban environment and the quality of life especially where climatology favors outdoor activities and nightlife. In Greece, quality of life has been established as a legal concept protected by the Constitution (Article 24). Quality of life is characterized by the soundscape, which contributes to the aesthetic quality of outdoor space. The existing Greek legislation deals with environmental noise on the basis of a rather quantitative approach, that is max. permissible levels per source, and does not clearly take into account a wider conception of the acoustic environment. The realization of the need for legal cover of environmental acoustic landscape protection has led to the creation of an autonomous branch of law, that of environmental law, which has recently introduced regulations regarding anti-noise planning, and the implementation of the Environmental Directive 2002/49/EC. Moreover, environmental noise in tourist cities is not fully covered by relevant laws. Only partial legal texts were implemented due to the difficulty of establishing laws aiming at the protection of the quality of life which is closely related to the rhythm of the Mediterranean city urban structure and life, the local economic model, various cultural and meteorological parameters, as well as the inhabitant and tourist perception of the noise climate. Quality of life in relation to the acoustic environment concerning recreation activities can be achieved using appropriate criteria regarding sleep quality and sleep disturbance. It is this need for a comprehensive legal framework that led to the creation of environmental law, whose primary purpose is the all-encompassing legal approach of the environmental noise problem. The basic characteristics of this type of law are its intense pragmatic and empirical character, its dependence on EU legislation and its close relation to economic growth and technology.

Keywords: environmental law, environmental noise, noise annoyance, soundscape, touristic areas.
\end{abstract}

\section{INTRODUCTION}

In South European (SE) and Mediterranean cities, urban development is the main source of acoustic annoyance and soundscape degradation; therefore, an appropriate legal framework aiming at the solution of those problems is imperative, with emphasis on:

- protection against urban environmental noise,

- re-evaluation of the acoustic landscapes, introducing noise as a major design parameter for all future developments,

- implementation of various mitigation measures aimed at the protection of the acoustic environment and the rehabilitation of urban space within a context of a global and multidisciplinary action according to the cultural and physical particularities of a city, and

- re-organization of the legislation and administration context of a European city by ensuring simultaneously all psychosocial characteristics and lifestyles of the relevant urban populations.

\section{BASIC GUIDELINES OF THE GREEK ENVIRONMENTAL NOISE LEGAL FRAMEWORK}

In Greece, environmental noise protection is constitutionally established with article 24 part 1 of the Constitution, which states: 'Environmental protection is a State obligation. The State is obligated to take special preventative or rehabilitation measures for its preservation' [3]. The environment that 
requires protection is the natural, cultural and constructed one, for which two stages of design are predicted, physical and urban planning and organization. Hence, the primary recipient of the environmental right is the State and all of its authorities: legislative, administrative and judicial ones, which should not act in a way that mistreats the environment or its protection while protecting it, either preventatively or curatively. As the Constitution authorizes, laws and regulatory administrative decisions have been published which deal with the protection of the natural environment, with physical and urban planning, and with the protection of architectural heritage. The principal law dealing with the natural environment is Law 1650 of 1986 'on environmental protection', which classifies projects and activities under the following main categories:

- Projects with a high environmental impact factor for the execution of which, a physical planning license and an Environmental Impact Assessment (EIA) study is required.

- Projects with a medium impact factor which do not have serious consequences on the environment. - Projects with a low impact factor.

For projects of a lower impact an approval of environmental protection conditions by submission of basic documentation is sufficient. Additionally, this law calls for Special Environmental Studies for objects of special protection where environmental noise is considered as a component of environmental pollution production and rules that with an administrative act it is possible to:

- limit values of noise levels in private and public spaces and buffer zones around existing or new areas of industrial installations, roads, ports, airports, archaeological or historical areas and landscapes and residential areas, as well as the limits of the noise levels at them, and

- limit values of noise and vibration levels for all types of vehicles, machines and instrumentation that are produced, introduced and circulated in the market or are used and create a noise annoyance.

Furthermore, all noise-producing projects and activities are identified, that is industry, factories, quarries, etc. and classified according to the noise annoyance that they cause under one of the previously mentioned categories. EIA contains special articles dealing with noise and, more specifically, with whether the construction of a particular project contributes to the increase of the existing noise level or with whether people are exposed to higher noise levels. In these studies, the following have to be assessed:

- The expected noise levels during the operation of the installation operation day and night.

- The noise characteristics (whether it is continuous or not, and its duration).

- The projected measures of noise control.

- Any secondary causes of possible increase in noise levels.

Environmental noise, in Greece and also in other SE and Mediterranean countries is an important factor that affects and is affected by urban planning; therefore, urban planning regulations, town plans, land uses, terms and manner of building construction as well as building materials significantly contribute to noise combating [4]. The combination of all these regulations is in short the general institutional framework for noise combating. Furthermore, a significant contribution to environmental protection is made by the jurisprudence of the Supreme Administrative Court, based on which the State Council controls the administration and interprets comprehensively the relevant provisions. Additionally, in noise protection administrative authorities, their reaction and law enforcement 
procedures play an important role. In Greece, the general responsibility in matters of environmental noise protection and urban planning is held by the Central Government and, more specifically, by the Ministry of the Environment, Energy and Climate Change (YPEKA) and by its decentralized regional services. Recently, with the restructuring of the Regional and Local Government, several responsibilities were given to its Departments. However, the complete and effective organization for the implementation of these responsibilities have not yet been created. Despite the fact that the legislative framework is sufficient, its application presents shortcomings, primarily for the following reasons:

- The principal law for environmental protection and, specifically, its regulations for noise are insufficiently applied, because the necessary relevant regulatory acts have not yet been issued.

- The acoustic scenery, either in the form of 'sound', in which case it has to be protected, or in the form of 'noise', in which case it is a pollution parameter, is not taken into account during the process of urban planning and in the determination of land uses.

- The regulations are distributed across various laws and have non-coherent characteristics; furthermore, an overlay of duties exists between various authorities, leading to the creation of confusion.

- Under the recent Greek Local Government re-organization scheme 'Kalikratis', the regional authorities had many responsibilities transferred to them (i.e. noise from bars and discos, etc.). However, they have neither the specialized personnel nor the appropriate material and technical infrastructure.

\section{A BRIEF OUTLINE OF THE GREEK ENVIRONMENTAL NOISE AND VIBRATION LEGISLATION}

The determination of appropriate criteria and relevant limits for acceptable noise and vibration levels for building protection and the elimination of human annoyance arising from mainly the construction of transportation projects in Greece have not yet been fully assessed or included in the existing Greek noise abatement legislation. It is also important to underline the need for the protection of extremely fragile ancient Hellenistic and Roman ruins and monuments.

Regarding airborne noise criteria in Greece, the following indices and max. permissible limits are included in the existing legal framework:

a. For industrial noise, the relevant noise limit in the boundary of the given installation is given in Table 1.

b. For road traffic noise: (i) the noise index $\mathrm{L}_{\text {eqA }}$ (equivalent continuous sound level), for the period 08.00-20.00 h. $\leq 67 \mathrm{~dB}(\mathrm{~A})$ and (ii) the index $\mathrm{L}_{10}(18 \mathrm{~h}) \leq 70 \mathrm{~dB}(\mathrm{~A})$.

c. Regarding vibration from metro, tramways and light rail networks operation the existing vibration velocity (peak particle velocity (PPV) in $\mathrm{mm} / \mathrm{s}$ ), seems to be the best descriptor which can be used to characterize the potential for building damage [5]. Regarding rail transportation networks operation, the following noise and vibration criteria are considered:

Table 1: Relevant noise limit.

\begin{tabular}{lc}
\hline Land use & Max. permissible $\mathrm{L}_{\max }$ limit \\
\hline Legislated industrial areas & $70 \mathrm{~dB}(\mathrm{~A})$ \\
Areas where industrial uses are dominant & $65 \mathrm{~dB}(\mathrm{~A})$ \\
Areas where industrial and residential uses are in equilibrium & $55 \mathrm{~dB}(\mathrm{~A})$ \\
Areas where residential uses are dominant & $50 \mathrm{~dB}(\mathrm{~A})$ \\
\hline
\end{tabular}


Recent EIA studies in Greece regarding metro and railway networks construction suggest the use of the above criteria as well as specialized criteria for human annoyance based on relevant British standards [6, 7]. Especially regarding vibration from construction activities [8], aiming the protection of ancient monuments of high cultural value and ensuring avoidance of vigorous community complaints the following criteria were also introduced:

- Max. permissible ground-borne noise level from train operation inside the dwelling or other under protection - building, $40 \mathrm{~dB}(\mathrm{~A})$ in the frequency area of 10-200 $\mathrm{Hz}$.

- Max. permissible ground-borne noise level from train operation in the proximity of sensitive buildings (as theatres, concert halls, etc.) $35 \mathrm{~dB}(\mathrm{~A})$ in the frequency area of 10-200 Hz.

- Max. permissible particle vibration velocity from train operation inside protected houses or buildings $0.5 \mathrm{~mm} / \mathrm{s}$ in the frequency area of $10-100 \mathrm{~Hz}$.

- Max. permissible particle vibration velocity from train operation near archaeological sites and ruins: $0.2 \mathrm{~mm} / \mathrm{s}$ in the frequency area of $10-100 \mathrm{~Hz}$.

The institutional framework for noise protection is included in the national legislation including the implementation of environmental assessment studies, the licensing processes and statutes that specify noise limits per activity and source and set terms and conditions for operation using the level of noise emitted as the criterion. Statutes regarding the observance of noise limits and the control and imposition of sentences in relative infringements [3] also exist. In general, the Greek legal framework refers to:

- noise from transportation (road traffic noise, aircraft-airport noise, noise and vibrations from constant orbit means),

- noise from industrial, mechanical installations and other professional activities,

- noise from social activities (entertainment, etc.), and

- permitted or even desirable noise emissions per source (vehicle, machinery, etc.) with respect to European Directives.

While, for the noise sources mentioned above, relevant directives have been issued by the EU, which Greece has adopted, it is for the first time the European parliament and the Council drew up and legislated a directive (2002/49/CE - already under revision and updating procedures) aimed at determining a common European approach for the avoidance, prevention and restriction of unfavorable effects, nuisance included, of exposure to environmental noise. A brief presentation of the major laws and regulations for environmental noise $[9,10])$ regroups:

- a principal law on the 'Protection of the Environment', dealing with the protection of the environment, dealing with noise as a component producing environmental pollution and considers that with the relevant administration actions is possible to determine - among other - the relevant marginal values of noise levels in private or public spaces, noise buffer zones protecting existing or new areas of industrial installations, streets, harbors, airports, archaeological or historical areas and landscapes and residential areas, the prohibition of the existence of materials and equipment in the market, intended to be used for the abatement of noise or vibrations if they do not fulfill the appropriate standards, etc. and

- a series of Joint Ministerial Decisions, regarding the content of 'EIA studies', based on a detailed classification of public and private works and activities in categories, and the determination of indicators and maximum permitted noise limits, that come from circulation of on-road and other transportation works and the protection of the general public from noise annoyance. 
Progress in legislative framework in Greece was quite extensive over the last decade. The local Government Authorities, regrouping extensive responsibilities regarding noise control from entertainment facilities, dispose now specialized personnel and the necessary technical infrastructure. Additionally, a special legal framework has also implemented the necessary noise emission standards, conformity assessment procedures of marking technical documentation and data collection relating to noise emitted into the environment by equipment for outdoor use.

However, major improvements are necessary especially in view of the latest Environmental Directive 2002/49/EC. It seems that the fundamental contradiction between urban development and the quality of the acoustic environment is formed with the desire to meet population needs and the resulting influence on environmental characteristics thus creating the need for a comprehensive and adequate legal framework which will ensure the abatement of all noise pollution effects that degrade the quality of life of both inhabitants and visitors. This often obliges them to abandon traditionally residential areas, resulting in radical cultural changes in their historical character and affecting the proper sustainable use of these areas. This outcome is a very important factor in quality of life especially in SE countries, where the special lifestyle and the tourist industry creates an urban context requiring very specialized legal actions.

\section{TOURISM AND ENVIRONMENTAL QUALITY - THE CASE OF THE GREEK ISLANDS}

The debate as to whether or not tourist-related activity is beneficial or detrimental to the host country is often discussed within the context of 'sustainability', where the emphasis is on carrying capacity, long-term viability and generally avoiding 'soiling one's own nest'. A factor in the development of tourist activities is environmental quality, bearing in mind that when at a good level it is a lever for the development of tourism and a magnet for tourist movement.

At the same time, environmental degradation acts as a counter-motive and leads to the reduction of tourist numbers. The contribution of mass tourism to the phenomenon known as the "environmental crisis' was recognized many years ago, and was noted in the Global Conference for Development and the Environment in Rio (1992), where it was felt necessary to take measures to deal with the degradation phenomena. The degradation of the acoustic environment in areas with developed tourism activities is associated with [11] transportation (road, air, rail and seaport activities), recreational activities and implications of the above on the land use patterns.

For the preservation of the soundscape in touristic urban areas, sustainability reference values (SRVs) need to be developed and established on a pan-European scale and agreed mainly on a scientific basis to be either safe or acceptable or tolerable for human health and the welfare of both the inhabitants and the visiting population. Targets associated with the SRVs should be identified by the driving forces, and the acceptability of the noise level should be developed on the basis of the outcome of the existing working groups set for the EU Noise Policy preparation and agreed by both EU and non-EU member states in the SE and Mediterranean regions.

The seasonal increase in tourist transportation affects the acoustic environment of the areas when considerable increase in road traffic flows need to be accommodated in often inadequate local infrastructure. This affects primarily the permanent residents who are not accustomed to it, but at times affects the tourists as well due to the proximity of some lodgings (especially in small- and mediumsized villages) to the principal road system. Similar effects can be experienced with air transport which is preferred for long-distance travel.

In Greece, where over $70 \%$ of tourists use air travel, normal flight numbers increase during the summer months by approximately 20-fold in the city of Rhodes and 10-fold in Mykonos. According to most studies, road traffic noise is the primary cause of tourist annoyance as compared with other 
noise sources and other annoyance factors, especially for those residing close to busy roads. Motorcycles and mopeds represent a particular annoyance parameter because of their intensified use due to the recent financial crisis. This use is often coupled with neglected maintenance, tampering, etc. The number of people using such a cheap mode of transportation in the warm Mediterranean climate during summer period increases and creates a lot of noise disturbance problems.

The city of Rhodes, already 15 years ago, initiated a large program of rehabilitation of acoustic landscape (which was the first of its kind in Greece at the time). Within this program, the main effort of the city was the execution of comprehensive global programs taking into account the differences of sensibility and annoyance due to noise both for the local inhabitants and visiting tourists mainly from northern European countries. The first Noise Map of the city was executed during the 90's and up until now various studies and actions have been realized including multinational projects with other SE cities (i.e. Barcelona, Modena, Zaragoza, etc.). During recent years, the city has implemented a number of global programs and the use of anti-noise measures of different types of application in relation to differences in the reactions to noise of both inhabitants and tourists, who are mainly from Northern European countries.

A considerable diminution of urban noise indices was detected, which for the index $\mathrm{L}_{\mathrm{eq}}$ day was established from $74.1 \mathrm{~dB}(\mathrm{~A})$ to only $69.4 \mathrm{~dB}(\mathrm{~A})$. The city of Rhodes action plans for rehabilitation of the urban acoustic environment consists mainly of the proper valorization of the sound quality of spaces, referred to as 'space spirit', and which is of main importance for tourist zones to take into account to maintain an upper grade of acoustic quality. Figures 1 and 2 show the improvement of the tourist population reaction to noise quality in the city as well as the importance of noise as a major descriptor of the city's quality of life $[12,13]$.

In order to identify the effects on the acoustic environment of activities related to tourism, a monitoring program during August 2000 was executed at Hora in Mykonos [13, 14]. The program aimed to determine the spread of influence and tests were repeated during the morning, evening, night and the early hours of the morning, in order to estimate the fluctuation of noise levels regarding the activities. Regarding the impact on the acoustic environment concerning the activities mentioned above it was noted that:

- Traffic: the majority of traffic was related to tourism activities. The impact on the acoustic environment was evaluated as significant at the areas next to roads that served movements to parking areas near recreation activities and the bus terminal $\left(\mathrm{L}_{\mathrm{eq}}>69, \mathrm{~L}_{\max }>88, \mathrm{~L}_{95}>50 \mathrm{~dB}(\mathrm{~A})\right)$.

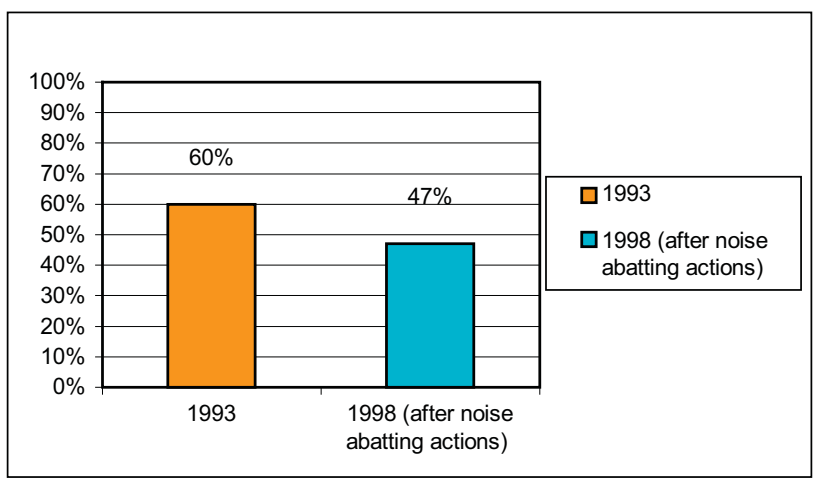

Figure 1: Percentage of tourists expressing a negative opinion for the acoustic environment. 


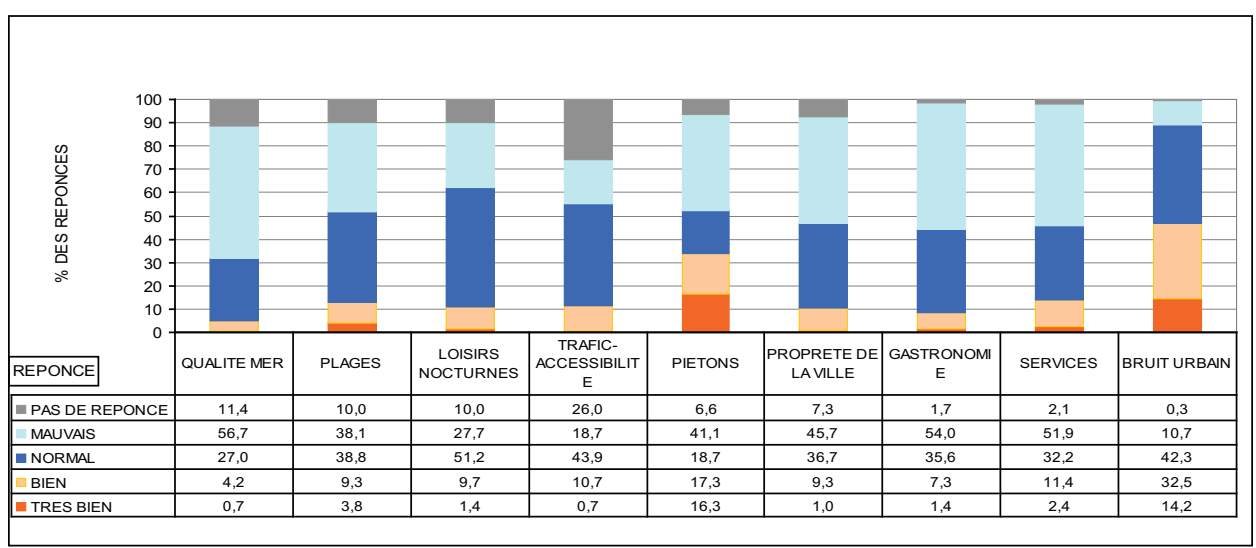

Figure 2: Distribution of responses evaluating the quality of the urban environment in the city of Rhodes.

The continuous presence of a large number of people at the bus terminal and the big number of busses, generated higher noise levels than other relevant places (daytime: $\mathrm{L}_{\mathrm{eq}}>+9, \mathrm{~L}_{\max }>+8$, $\mathrm{L}_{95}>+7 \mathrm{~dB}(\mathrm{~A})$ and in nighttime: $\left.\mathrm{L}_{\mathrm{eq}}>+4, \mathrm{~L}_{\max }>+4, \mathrm{~L}_{95}>+13 \mathrm{~dB}(\mathrm{~A})\right)$. During the night, noise levels were higher next to roads mentioned above, due to an increased number of motorbikes and an often noisy driving behavior. Motorbikes and three-wheeled vehicles traffic on the inner town road network, affected the acoustic environment by a considerable increment $\left(\mathrm{L}_{\mathrm{eq}} \geq+6 \mathrm{~dB}(\mathrm{~A})\right.$, $\mathrm{L}_{\max } \geq+4 \mathrm{~dB}(\mathrm{~A})$ ), since background noise level was increased considerably $\left(\mathrm{L}_{95} \leq+1 \mathrm{~dB}(\mathrm{~A})\right.$ ).

- Recreation: the majority of activities were related to tourism. The impact on noise levels varied during daytime and in relation to the category of recreational activity. On the other hand, there was no significant variation on the acoustic environment during the day from recreational activities, (variation of $\mathrm{L}_{\text {eq }} \leq+3 \mathrm{~dB}(\mathrm{~A})$ ), $\mathrm{L}_{95} \leq+3 \mathrm{~dB}(\mathrm{~A})$ ) and they were less important than during the night. Noise level aggravation in the nighttime compared with daytime in terms of average values was important for background noise $(+13 \mathrm{~dB}(\mathrm{~A}))$ and $\mathrm{L}_{\mathrm{eq}}(+8 \mathrm{~dB}(\mathrm{~A}))$ but not for $\mathrm{L}_{\max }$ values $(+2 \mathrm{~dB}(\mathrm{~A}))$. The worst case regarding noise occurred in places where an increased number of bars, clubs, etc. were located. The impact from recreational activities on noise level was less important in comparison with traffic impact during daytime, but was considerably worse for background noise during night in particular $(+11 \mathrm{~dB}(\mathrm{~A})$ increment) because of continued loud music and the crowd that gathered.

- Residential: there was significant variation regarding the acoustic environment in residential areas related to the vicinal land uses. At places where the main land use was residential and the influence from traffic and recreation was low (places out of direct vicinity of bus terminal area, main road network and recreation areas), the quality of acoustic environment was satisfactory. Noise level during the night was lower than during the day (the level of reduction was $7 \mathrm{~dB}(\mathrm{~A})$ for $\mathrm{L}_{\text {eq }}$, $2.6 \mathrm{~dB}(\mathrm{~A})$ for $\mathrm{L}_{\max }$ and $4 \mathrm{~dB}(\mathrm{~A})$ for $\mathrm{L}_{95}$ ). In residential areas located next to places of recreational activity, the worst location was understandably the first block which had an unobstructed view to areas mentioned above. The situation improved as distance from recreation areas increased and there was a reduction of direct view. Even at second parallel to linear recreation activities along an inner city road (no direct view to recreation places), the acoustic environment improved considerably and at third parallel the situation was quite similar to uninfluenced residential areas. At places near recreation areas, even where noise levels were low, it was easy to distinguish the 
music from open clubs and bars. It should be mentioned that the traditional complex building system (narrow roads, etc.) helps to absorb noise. Due to community restriction, music stops after 3:00 pm, and that helps in noise level reduction (third parallel: $-2 \mathrm{~dB}(\mathrm{~A})$, background noise, $\mathrm{L}_{\mathrm{eq}}$ $-1 \mathrm{~dB}(\mathrm{~A})$ ). Pedestrian passage through the residential areas (returning after entertainment) had a negative influence on noise level increasing the value of $\mathrm{L}_{\max }$ index (approximately $+14 \mathrm{~dB}(\mathrm{~A})$ ).

Furthermore, regarding the quality of life in relation to acoustic environment concerning the activities mentioned above and criteria about sleep quality and disturbance prevention in residential areas it was noted that:

- Sleep quality: the criterion was 'Conditions that ensure satisfactory quality of sleep during the night with open windows were: (a) external noise should not exceed the noise level limits. $L_{e q} \leq$ $45-50 \mathrm{~dB}(A), L_{\max } \leq 60 \mathrm{~dB}(A)$ '. The variation of noise levels was more disturbing and had a more powerful effect on night sleep when related to the intense variation from background noise. Sleep quality was considered satisfactory in residential areas away from the vicinity of recreational activities and traffic (noise levels during night are low). At places near areas with recreation activities, sleep quality was considered almost satisfactory, after the second parallel road, where background noise and $\mathrm{L}_{\mathrm{eq}}$ level were low, but there was a random negative factor that influenced the $\mathrm{L}_{\max }$ level and that was the pedestrian passage and their behavior. Next to recreational activity areas and roads with traffic noise level conditions generated unfavorable situations regarding sleep quality (considerable high noise level during night $\mathrm{L}_{\max }$ and background noise).

- Disturbance prevention at residential areas: the criterion was ' $L_{e q}$ value should not exceed the level of 50-55 $d B(A)$ at which disturbance starts occurring during daytime and at $45 d B(A)$ during nighttime'. Conditions observed seem to be satisfactory in terms of the criterion above at residential areas away from the vicinity of recreational activities and traffic $\left(\mathrm{L}_{\text {eq }}\right.$ levels were close to the criterion levels). At places near areas with recreation activities, conditions observed seem to be satisfactory at places after the third parallel road. Next to recreational activity areas and roads with traffic, noise level conditions possibly generated disturbing situations to residential land uses.

So in Hora in Mykonos, due to the spatial distribution of land uses related to tourism (such as recreation and traffic) at specific locations which were not near the residential areas, the overall situation of the acoustic environment was quite satisfactory. The enforcement of the restrictions regarding the music in bars in the inner town (in out of town and residential areas there were no restriction) and traffic seemed to be efficient in achieving a quality acoustic environment. Furthermore, appropriate measures should be considered for noisy motorbikes and land use mixtures.

\section{RECOMMENDATIONS}

The often unplanned and extensive use of space in order to accommodate more activities will eventually degrade the urban acoustic environment, which is one of the primary attraction points. In simple words, excessive activities will severally damage the urban environment. In fact, for some places the necessity for immediate introduction of global acoustic environment sustainability indicators is more than obvious. Financial contributions are being made to a limited number of initiatives by the urban area authorities and this trend should be further developed. However, for sustainable acoustic landscapes in the cities, there is a need to better understand not only the benefits but also the costs of an uncontrolled development. 
The European Commission, the European Environment Agency and the EU Member States aligned to the requirements of the END (Environmental Noise Directive) relating to the assessment and management of environmental noise [1] have been intensifying their efforts to face the big challenge and opportunity to make available to the European citizens reliable information on the noise levels they are exposed to and the associated health implications, and to draw appropriate action plans for preventing and reducing exposure to harmful levels of environmental noise.

The END establishes in article 6 that common assessment methods for the determination of the environmental noise indicators $\mathrm{L}_{\text {den }}$ and $\mathrm{L}_{\text {night }}$ will be defined for use in the EU member states, to ensure consistency of noise exposure data among Europe, and to achieve accuracy, precision and credibility of the assessment performed throughout the EU and in the estimation of the population exposure. The Institute for Health and Consumer Protection (IHCP) of the Directorate General Joint Research Centre (JRC) of the European Commission is supporting the Directorate General for the Environment (DG-ENV) in the preparation of Common NOise ASSessment MethOdS (CNOSSOS) for road, railway, aircraft and industrial noise to be used for producing strategic noise maps and relevant action plans in order to improve the reliability and the comparability of results across the EU member states.

For whatever concerns Greek legislation, the particular duties of noise measurements and inspection checks from regional authorities, need to be thoroughly revaluated in order to eliminate overlapping of jurisdiction and avoid confusion. Particularly, under the recent re-organization scheme 'Kalikratis', regional authorities must redeploy specialized personnel and establish the appropriate technical infrastructure for noise measurements and control.

For the comprehensive investigation of the urban soundscape, and for other goals derived from urban planning, it is essential for environmental impact studies to precede the two phases of urban planning, that is 'General Urban Plans' and 'Specific Urban Studies' (urban plans, local plans) before their approval, in order to identify, assess and propose measures for dealing with the environmental impacts which will be brought about by these plans on the impacted area as well as on neighboring areas. In this environmental control, primarily at the level of General Urban Plans and urban planning studies, where land use distribution is made and where building regulations are imposed, the protection of the acoustic environment has to be taken into account. More specifically, as far as an area is concerned, it is necessary to decree max. permissible noise levels (per noise source and per land use), to foreseen buffer zones by using as a standard the reduction of annoyance and the residents' health protection as well as the protection of the acoustic landscape, to correlate land uses according to annoyers and annoyed from a noise viewpoint, to regulate maximum noise levels for annoying uses according to the current legislation and to introduce rules, if necessary, of temporal noise management using the reduction of noise pollution as the principal standard.

Regarding the character and extent of action plans which are negotiated and decided locally, that is at member state, region or municipality level (the END states clearly that 'noise action plans are at the discretion of competent authorities'), the relevant purposes are [15]:

- to identify priorities (e.g. important areas) and 'best' actions,

- to involve the general public in options to improve the noise quality, and

- to reflect future developments, for example local effects of community measures such as sourceoriented noise policy.

Environmental noise mapping information needs to be consistent and comparable all across Europe, from one member state to another, from one agglomeration to another, from one reference year to another. 
This basic concept does not recommend that every member state uses its own method to assess noise exposure. The consistency requirement, however, does not extend to national legislation, national or locally set legal limits, national or local indicators, nor to the extent and character of action plans. Because of this consistency requirement, the common approach objective is clearly mentioned in the END. Consistency in results can be achieved through consistency in approach, definitions, input data and methods. Though simplifications can be assumed in the calculation method at the base level, a minimum set of input data must be known for all sources to ensure comparability.

Additionally, there is a need to develop both a more systematic analysis of direct and indirect costs and benefits as well as green accounting approaches including the acoustical environment. Actions are needed at all policy levels, international cooperation which should involve EC bodies should therefore play a fundamental role in the field of policy, research and information gathering through adequate resources directed to activities in the region.

There is a need for reassessing conventions, framework agreements, procedures and protocols; financial mechanisms, such as taxes on the environment, for all pollutant activities, that is transportation, tourism, etc., requirements to reinvest profits in regions with noisy installations and activities, fines for non-compliance, subsidies for the environmental upgrading of facilities, development of eco-tourism, technical assistance and advice and land use planning and protective laws for all SE urban regions and especially in Greece, where it is important to take into consideration the environmental noise abatement needs.

Better integration of a global Mediterranean sustainable development demands major efforts regarding awareness raising, training and exchange of experience and best practices, as well as the organization of strong local participation.

Tourism is a vital economic sector for the existence of many SE Mediterranean coastline areas. Noise in these areas can affect the quality of life for both tourists and locals. In that respect, environmental noise management and urban soundscape rehabilitation should be compulsorily included in all environmental considerations. Action is also needed through legal and financial mechanisms to enable urban authorities to contribute to the acoustic quality thus supporting much-needed economic development in the SE and Mediterranean regions.

\section{REFERENCES}

[1] Hatzopoulou, A., Chaikali, S., Existing noise abetment legislation in Greece and proposed legal framework towards a rehabilitation and management of the acoustic landscape, Internoise 2000, Nice, France, August 2000.

[2] Vogiatzis K., Noise mapping in Greece and the psychosocial parameters of Mediterranean countries, Internoise 2000, Nice, France, August 2000.

[3] Vogiatzis K. \& Mouzakis H., Criteria for vibration from railway \& light rail transportation projects construction for the protection of buildings and the avoidance of annoyance, Epistimoniko Ktirio, B/1999, pp. 57-59.

[4] British Standard BS 7385, "Evaluation and Measurement for Vibration in Buildings", Part 1. Guide of measurement of vibrations and evaluation of their effects on buildings, Part 1: 1990, ISO 4866: 1990.

[5] British Standard 6472, Evaluation of human exposure to vibration in buildings ( $1 \mathrm{~Hz}$ to $80 \mathrm{~Hz}$ ), 1992.

[6] Von Gierke, H.E., Guidelines for Preparing Environmental Impact Statements on Noise, Committee on Hearing, Bioacoustics, and Biomechanics Assembly for Behavioral and Social Sciences (CHABA), Working Group 69, For : National Research Council, NTIS AD A044384, 1977. 
[7] Vogiatzis, K., Chaikali, S. \& Siouti, Gl., Environmental Noie Protection in Greece, Recent Legal Framework \& Action Tools, 18th International Congress on Sound and Vibration (ICSV18) Rio de Janeiro, Brazil, 10-14 July 2011.

[8] Vogiatzis, K., Chaikali, S., Chatzopoulou, A., Existing Legal framework for the environmental acoustics in Greece, 12th International Congress on Sound \& Vibration, Lisbon 11-14 July 2005.

[9] Vogiatzis, K., Psychas, K. \& Vallet, M., A social noise survey in the holiday city of Rhodes, Noise \& Man Congress Nice 1993, pp. 615-618.

[10] Frantzeskakis, J., Vogiatzis, K., Hatzopoulou, A., Aravantinos, A. et al. Programme for Noise Abatement in Tourist Areas Final report, Dept. of Transportation Planning and Engineering of the NTUA, for the Ministry of Environment, Planning and Public Works, Direction of Air Pollution and Noise Control, Section of Noise Abatement, October 1999.

[11] Frantzeskakis, J., Vogiatzis, C., Simantonis, J., Rehabilitation of the acoustic environment of the city of Rhodes, INTERNOISE 2000, Nice France, August 2000.

[12] Vogiatzis, K. Chonianaki, F., Acoustic climate in tourist traditional settlements in Greek islands - The case of Mykonos, The 2001 International Congress and Exhibition on Noise Control Engineering The Hague, The Netherlands, August 27-30, 2001.

[13] Directive 2002/49/EC of the European parliament and of the Council of 25 June 2002 relating to the assessment and management of environmental noise.

[14] Commission Recommendation of 6 August 2003 (2003/613/EC) document number C(2003) 2807 Official Journal EU L 212/49.

[15] Bento Coelho, J.L., Vogiatzis, K., Licitra, G., The CNOSSOS-EU initiative: A framework for road, railway, aircraft and industrial noise modelling for Strategic Noise Mapping in EU member states, 18th International Congress on Sound and Vibration (ICSV18) Rio de Janeiro, Brazil, 10-14 July 2011. 